\title{
Presence of Turner stigmata in a case of dysgenetic male pseudohermaphroditism with 45,X/46,X+mar karyotype
}

Hiroyuki Hashimoto, Hiroaki Maruyama, Rie Koshida, Norihiko Okuda, Kazuo Murayama, Tetsuro Katsumi, Kishichiro Watanabe, Tamotsu Sato

\begin{abstract}
A case is reported of dysgenetic male pseudohermaphroditism (DMPH) having Turner stigmata and 45,X/46,X+mar karyotype. The marker chromosome of this patient consisted of most if not all of the short arm, including the sex determining region of the $Y$ chromosome. Although this karyotype is relatively common in Turner's syndrome and occasionally observed in mixed gonadal dysgenesis, DMPH is usually exemplified by a 46,XY karyotype except for one patient reported with $45, \mathrm{X} / 46, \mathrm{XY}$ mosaicism. Turner stigmata have not previously been reported in DMPH. The present patient is an intermediate case between mixed gonodal dysgenesis and typical $D M P H$, and this indicates that $45, \mathrm{X} /$ $46, X+m a r$ karyotype abnormality can result in a wide range of phenotype such as DMPH, mixed gonodal dysgenesis and Turner's syndrome.

(Arch Dis Child 1997;76:268-271)
\end{abstract}

Kanazawa National Hospital, 3-1-1 Ishibiki, Kanazawa 920, Japan: Department of Pediatrics H Hashimoto R Koshida

N Okuda

Department of

Urology

K Murayama

T Katsumi

Department of Pathology

K Watanabe

Department of Pediatrics, Kanazawa Red Cross Hospital,

Kanazawa, Japan

H Maruyama

Department of Medical Information, School of Medicine, Kanazawa University, Kanazawa, Japan

T Sato

Correspondence to: Dr Hashimoto.

Accepted 19 November 1996
Keywords: dysgenetic male pseudohermaphroditism; karyotype $45 \mathrm{X} / 46 \mathrm{X}+\mathrm{mar}$; Turner stigmata.

In 1967, Federman first described dysgenetic male pseudohermaphroditism (DMPH) as a rare disorder of sexual differentiation caused by embryogenic failure in the normal processes of testicular differentiation. ${ }^{1}$ This syndrome is characterised by bilateral dysgenetic testes, persistent internal müllerian duct structures, cryptorchidism, and inadequate virilisation, and is classified at present as a form of male pseudohermaphroditism. ${ }^{1-3}$ Patients with mixed gonadal dysgenesis (MGD), which is a more common disease than DMPH and characterised by a unilateral dysgenetic testis and a contralateral streak gonad, also show defective virilisation and persistence of the müllerian ducts. ${ }^{34}$ The risk of gonadal tumours, such as gonadoblastoma, has been estimated to be high in both patients with DMPH and MGD. ${ }^{23}$ From these findings, DMPH is thought to be closely related to MGD. ${ }^{235}$ Furthermore, it is thought that a close relationship also exists between MGD and Turner's syndrome because a $45 \mathrm{X} / 46 \mathrm{XY}$ karyotype, which is typical of MGD, ${ }^{46}$ is seen in Turner's syndrome, ${ }^{67}$ and features of Turner's syndrome are seen in patients with MGD. ${ }^{4}$ Although patients with $\mathrm{DMPH}$ reported on to date had a $46, \mathrm{XY}$ karyotype, ${ }^{12}$ except for one with $45, \mathrm{X} / 46, \mathrm{XY}$ mosaicism, ${ }^{6}$ and Turner stigmata have not previously been reported in classical DMPH, we here report a case of DMPH with Turner stigmata and $45, \mathrm{X} / 46, \mathrm{X}+$ mar karyotype, which is a relatively common karyotype in patients with Turner's syndrome. ${ }^{78}$ We investigated the loci of the $\mathrm{Y}$ chromosome, including the sexdetermining region (SRY) on the marker chromosome, by using the polymerase chain reaction (PCR) method. The aetiological backgrounds of sexual differentiation disorders related to testicular development are also discussed.

\section{Case report}

This phenotypic male infant was a $2332 \mathrm{~g}$ (appropriate for gestational age) product of a 37 week 4 day gestation with normal delivery in a 23 year old woman. His height at birth was $45.5 \mathrm{~cm}$ (1.5 SD below the mean for gestational age). He had ambiguous genitalia such as a small phallus with chordee, perineal hypospadia, bifid scrotum, and palpable gonad in the left scrotum. There was no lymphoedema over the dorsum of the fingers and toes. Chromosome analysis was performed on 40 peripheral blood lymphocytes of the patient using $\mathrm{G}$ banding, $\mathrm{C}$ banding, and $\mathrm{Q}$ banding. His karyotype was $45, \mathrm{X} / 46, \mathrm{X}+$ mar mosaicism (26 lymphocytes had 46,X+mar karyotype and the karyotype of the other 14 lymphocytes was $45, \mathrm{X})$. The non-consanguineous parents were clinically normal and the karyotype of the father was 46,XY. DNA analysis of a marker chromosome in peripheral blood lymphocytes using the PCR method was performed by Dr Yutaka Nakahori (Department of Human Genetics, School of International Health, University of Tokyo, Tokyo, Japan). A schematic map of the Y chromosome and loci investigated in this case is shown in fig 1 . The marker chromosome of this patient consisted of most if not all of the short arm, including the SRY locus and the centromere of the $\mathrm{Y}$ chromosome, while the bulk of the long arm of the Y chromosome was missing.

On radiography, computed tomography, and magnetic resonance imaging, a vagina between the rectum and bladder, and a gonad-like mass in the right inguinal region were detected but no uterus was observed (fig 2). This infant was reared as a male according to the parents' wishes after the risk of gonadal tumours had been explained to them. 


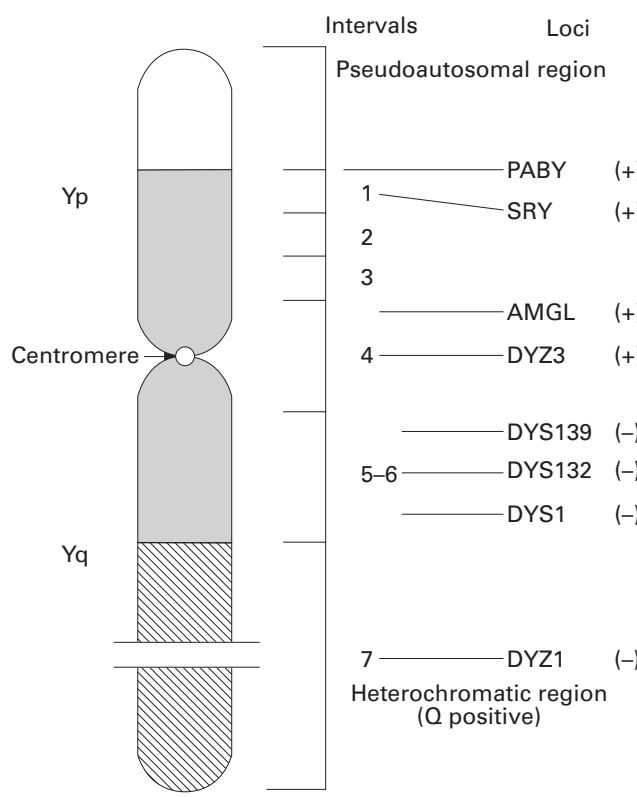

Figure 1 Schematic map of the Y chromosome with loci investigated in this case. $(+)$ indicates the presence of locus and (-) indicates the absence of locus on the marker chromosome. PABY, proximal border of the pseudoautosomal region of Y; AMGL, amelogenin-like sequence; $D Y Z$ and $D Y S, D=D N A, Y=Y$ chromosome, $Z=Z$-repetitive copy DNA, $S=$ segment, and the number indicates published order of specific cloned DNA sequence.

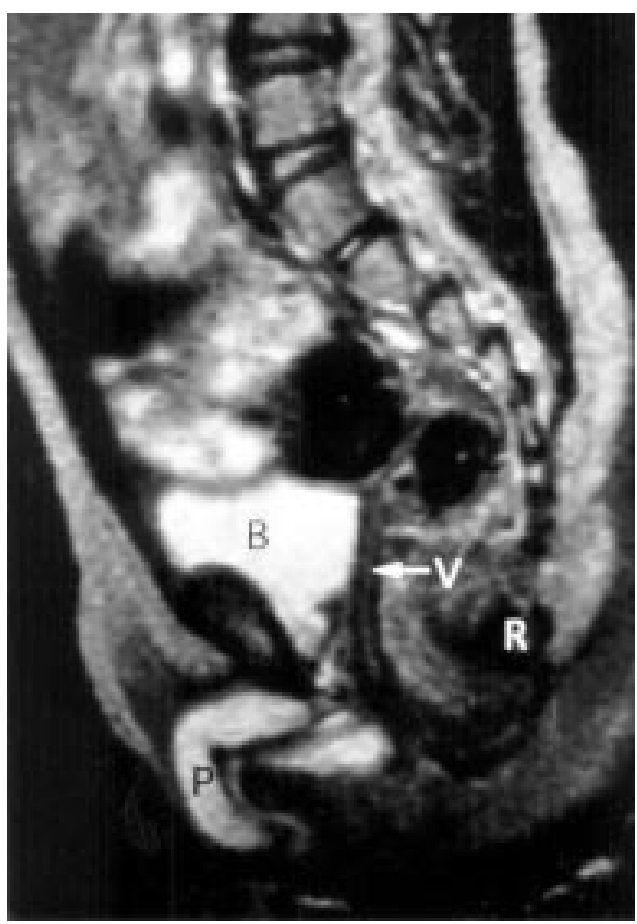

Figure 2 Magnetic resonance imaging at 2 years of age showing the presence of the vagina $(V)$ between the bladder $(B)$ and the rectum $(R)$ but the absence of a uterus. $P$ indicates phallus.

At 6 months of age, endocrinological examination showed that the serum luteinising hormone $(\mathrm{LH})$ concentration was $0.3 \mathrm{U} / 1$ (normal 0.02-0.3 U/1) and follicle stimulating hormone (FSH) was $2.7 \mathrm{U} / 1$ (normal 0.26-3.0 $\mathrm{U} / \mathrm{l})$. The serum level of testosterone increased from $<0.17 \mathrm{nmol} / 1$ (normal $0.10-0.35 \mathrm{nmol} / \mathrm{l}$ ) to $14.04 \mathrm{nmol} / 1$ (normal above twofold in- crease of basal value) by human chorionic gonadotrophin (hCG) administration. However, there was no response of serum oestradiol to human menopausal gonadotrophin stimulation.

At 28 months of age, the gonad-like mass and its appendixes in the right inguinal canal were resected. Histological examination revealed that this gonad-like tissue was testicular but its architecture was abnormal. Although a + tunica albuginea was present, ectopic seminiferous tubules were observed. The seminiferous tubules were disorganised and separated by oedematous stroma. There was no ovarian-like stroma or gonadoblastoma. In the appendixes, epididymis and fallopian tube were observed adjacent to the dysgenetic testis. A uterus was also detected by microscopic examination on the contralateral side to the dysgenetic testis (fig 3).

At 3.4 years of age, we diagnosed him as having DMPH because his scrotal gonad significantly responded to hCG stimulation (testosterone increased from 0.17 to 4.44 nmol/l). ${ }^{6}$ The response to $\mathrm{LH}$ releasing hormone was within the normal range (LH increased from $<0.1$ to $5.8 \mathrm{U} / 1, \mathrm{FSH}$ increased from 1.7 to $16.1 \mathrm{U} / \mathrm{l}$ ) found in children of corresponding age. His height was $86.2 \mathrm{~cm}(2.7$ $\mathrm{SD}$ below the mean for his age). Serum concentration of insulin-like growth factor I was $17.9 \mathrm{nmol} / 1$ (normal $5.88-30.07 \mathrm{nmol} / \mathrm{l}$ ) and urinary growth hormone concentration during sleep was $575.8 \mathrm{pg} / \mu \mathrm{mol}$ creatinine (normal above $79.2 \mathrm{pg} / \mu \mathrm{mol}$ creatinine). Serum growth hormone concentration was increased from 6.7 to $20.8 \mu \mathrm{g} / \mathrm{l}$ by intravenous administration of growth hormone releasing factor (normal peak value, above $15 \mu \mathrm{g} / \mathrm{l}$ ) and from 5.0 to $19.9 \mu \mathrm{g} / \mathrm{l}$ by arginine administration (normal peak value, above $10 \mu \mathrm{g} / \mathrm{l}$ ). These findings indicate that his short stature was not due to growth hormone deficiency.

At 3.8 years, urethroplasty was performed. At 4 years of age, his penis was very short (2 $\mathrm{cm})$ and left testicular volume was very much below the lower limit normal for his age $(<0.5$ $\mathrm{ml})$. Turner stigmata, such as short neck, mild webbed neck, broad chest, low set and posteriorly rotated ear, micrognathia, and low posterior hairline, were observed as shown in fig 4 . The short metacarpal of the fourth finger (fig $5 \mathrm{~A}$ ), cubitus valgus (fig 5B), and hyperconvex nails became apparent with growth. However, he had no cardiovascular abnormalities.

\section{Discussion}

This case report shows the variability of sexual differentiation in individuals with $45, \mathrm{X} /$ $46, \mathrm{X}+$ mar karyotype. This karyotype is the most common in Turner's syndrome. About $50 \%$ of patients with Turner stigmata show mosaicism, and a marker chromosome is present in $3 \%$ of such patients. ${ }^{8}$ Nagafuchi et al reported that marker chromosomes of 23 of 41 Japanese patients with Turner's syndrome with a $45, \mathrm{X} / 46, \mathrm{X}+\operatorname{mar}$ (37 patients) or $46, \mathrm{X}+$ mar karyotype (four patients) consisted of the short arm and centromere of the Y chromosome. As shown in our case, their break points were dis- 


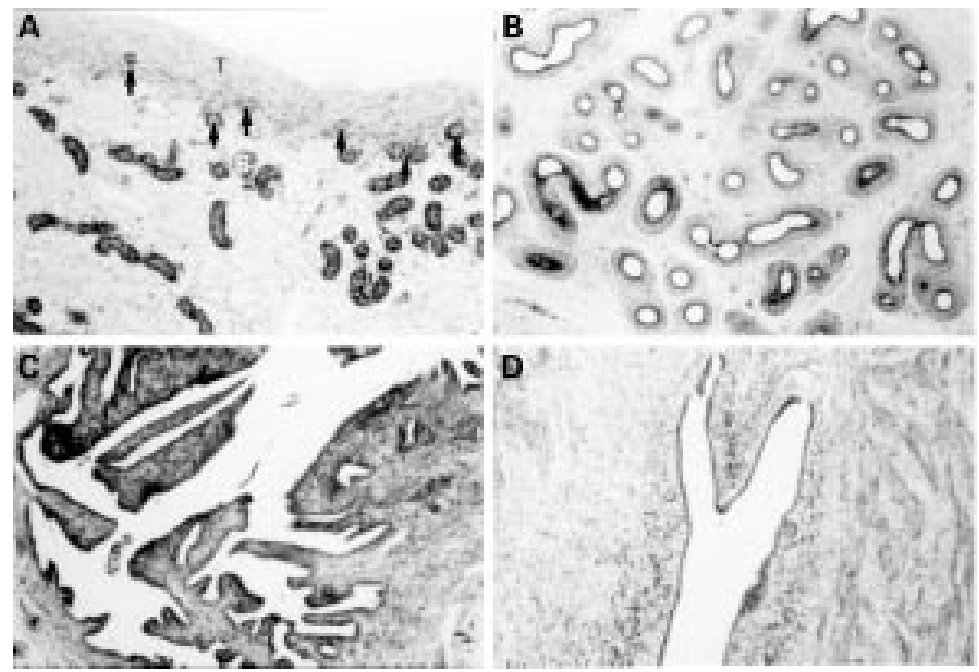

Figure 3 Histological sections of the right gonad $(A)$ and its appendixes $(B, C, D)$. (A) dysgenetic testis showing separation of disorganised seminiferous tubules ( $S$ ) by oedematous stroma and presence of the tunica albuginea $(T)$ with ectopic seminiferous tubules (arrow); (B) epididymis; (C) fallopian tube; (D) uterus.

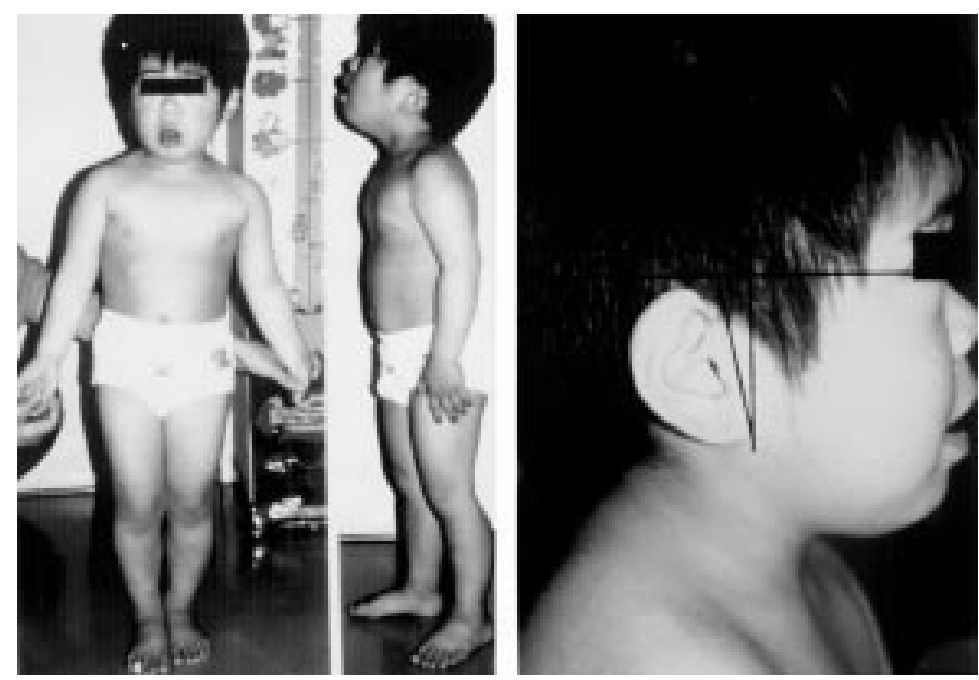

Figure 4 Photographs of whole body and face at 4 years of age. Short neck, mild webbed neck, broad chest, low set and posteriorly rotated ear, micrognathia, and low posterior hairline were observed. gonads such as clusters of granulosa-like cells. Their streak gonads were not histologically distinguishable from those found in patients with Turner's syndrome. Interestingly, one patient with MGD had primordial follicles within the ovarian portion of the dysgenetic testis. In addition, another patient with MGD had a single primordial follicle in the streak gonad. Of additional interest, two patients with $\mathrm{DMPH}$ had a cortex composed of ovarian-like stroma in their dysgenetic testes. These histological findings suggest that their dysgenetic gonads were ovotestes resulting from inadequate or delayed testicular determination during fetal life and, in the absence of two $\mathrm{X}$ chromosomes, the ovarian tissue would be expected to regress, leading to the subsequent appearance of a dysgenetic testis. On the other hand, absent testicular determination, resulting from the abolished function of SRY and other related genes, would permit ovarian differentiation of the gonads and finally lead to the streak gonads as seen in MGD, Turner's syndrome, and 46,XY pure gonadal dysgenesis. In addition, it is well known that the biological effect of antimüllerian hormone secreted by Sertoli cells leads to the regression of müllerian ducts, and the differentiation of both wolffian ducts and external genitalia is due to the effect of testosterone secreted by Leydig cells. Differentiation of these two cell types and the amount and timing of the secretion of these two hormones are important for sexual differentiation, as Kofman et al have established a correlation between endocrine findings with gonadal morphology and phenotype in patients with mosaicism. ${ }^{6}$

It has recently been recognised that the genes for Turner stigmata are present on the short arm of the $\mathrm{Y}$ and $\mathrm{X}$ chromosomes, and that haploinsufficiency of these genes results in the development of Turner stigmata. ${ }^{10}$ Even if the loci for Turner stigmata exist, a structurally abnormal sex chromosome may result in inactivation of them. ${ }^{11}$ Somatic growth is also thought to be controlled by the pseudoautosomal growth gene on Yp. ${ }^{12}$ On the other hand, the gene responsible for initiating testicular development in the fetal gonad is considered to be identical with SRY. ${ }^{13}$ These findings indicate that Turner stigmata have no relation to sexual differentiation and are the result of the deletion or inactivation of these genes. The presence of Turner stigmata in DMPH has not previously been demonstrated and the typical karyotype for $\mathrm{DMPH}$ is $46, \mathrm{XY}$, so we consider that the Turner stigmata seen in our patient may have resulted from his $45, \mathrm{X} / 46, \mathrm{X}+$ mar karyotype, which is normally seen in Turner's syndrome.

In addition, we consider that Turner's syndrome patients with a chromosome derived from Y, particularly SRY, should be regarded as having male gonadal dysgenesis, as the present case indicates that the streak gonads seen in Turner's syndrome patients with a Y chromosome may result from faulty testicular differentiation. At least, they should be distinguished from Y chromosome negative Turner's syndrome patients, as the gonadoblastoma locus is
MGD, and three with $\mathrm{DMPH}^{3}$ Two patients with 46,XY pure gonadal dysgenesis had evidence of ovarian differentiation of streak 

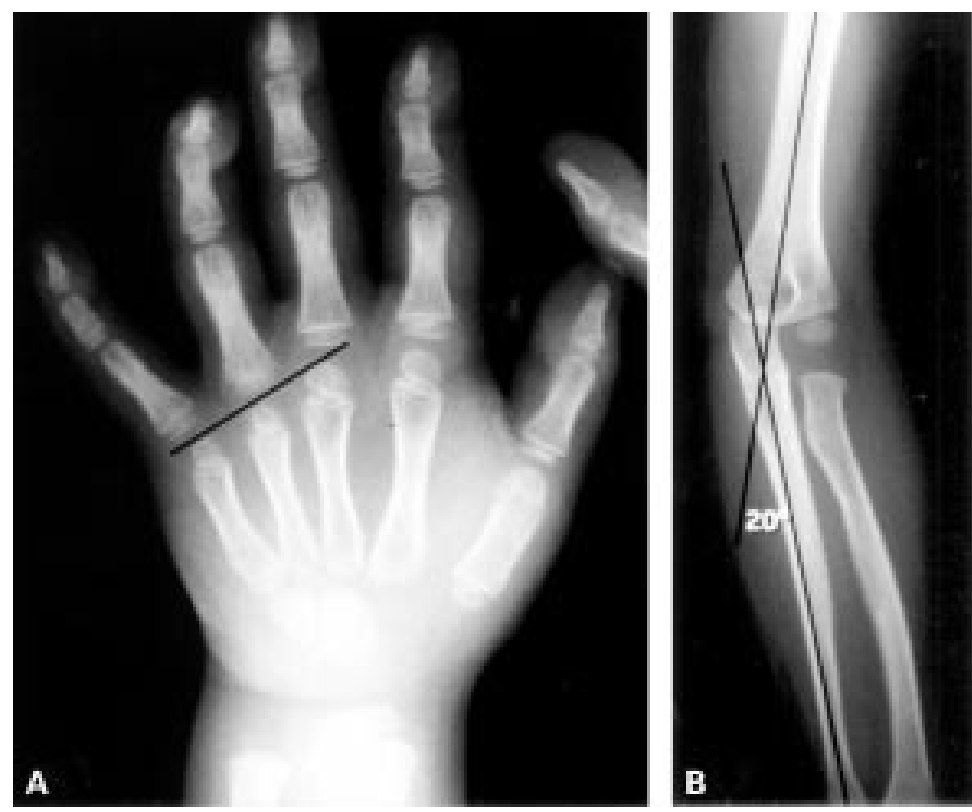

Figure 5 Radiographs taken at 4 years of age demonstrating a short fourth metacarpus (A) and an increased carrying angle (cubitus valgus) (B). In many patients with Turner's syndrome, the angle is between 15 and $30^{\circ} .{ }^{9}$

now thought to exist on $\mathrm{Yq}^{7}$ and, as seen in MGD and DMPH, a high incidence of gonadoblastoma has also been observed in patients with Turner's syndrome having a part of the $\mathrm{Y}$ chromosome. ${ }^{67}$ These results indicate that evaluation of the $\mathrm{Y}$ chromosome by molecular methods should be carried out in patients with a marker chromosome.

We consider that a single karyotype abnormality can result in a wide range of phenotypes, and that DMPH, MGD, and SRY positive Turner's syndrome may be alternative responses to almost the same abnormal genetic complement. The most important factors for gonadal and phenotypic differentiation may not be the karyotype or the ratio of mosaic cells including the $\mathrm{Y}$ chromosome ${ }^{6}$ but the expression of SRY and other related genes, the degree of testicular differentiation, and the amount and timing of antimüllerian hormone and testosterone secretion.

The authors wish to express their appreciation to Dr Yutaka Nakahori for DNA analysis of the marker chromosome.

1 Federman DD. Abnormal sexual development. $N$ Engl f Med 1967;277:51-60.

2 Rajfer J, Mendelsohn G, Arnheim J, Jeffs RD, Walsh PC. Dysgenetic male pseudohermaphroditism. F Urol 1978; 119:525-7.

3 Berkovitz GD, Fechner PY, Zacur HW, et al. Clinical and pathologic spectrum of $46 \mathrm{XY}$ gonadal dysgenesis: its relevance to the understanding of sex differentiation. Medicine 1991;70:375-83.

4 Yamakita N, Yasuda K, Mori H, Kuriyama M, Kumamoto Y, Miura K. A case of mixed gonadal dysgenesis (MGD), with a review of MGD patients reported in Japan. $7 p n$ f Med 1989;28:744-52.

5 Rohatgi M, Gupta DK, Menon PSN, Verma IC, Mathur M. Mixed gonadal dysgenesis and dysgenetic male pseudohermaphroditism: a critical analysis. Indian f Pediatr 1992; 59:487-500.

6 Kofman S, Pérez-Palacios G, Medina M, et al. Clinical and Kofman S, Perez-Palacios G, Medina $M$, et al. Clinical and
endocrine spectrum in patients with the $45, \mathrm{X} / 46, \mathrm{XY}$ endocrine spectrum in patients with
karyotype. Hum Genet 1981;58:373-6.

7 Nagafuchi S, Tamura T, Nakahori Y, et al. The majority of the marker chromosomes in Japanese patients with Turner syndrome are derived from Y chromosomes. Hum Genet 1992;89:590-2.

8 Robinson A. Demography and prevalence of Turner syndrome. In: Rosenfeld R, Grumbach MM, eds. Turner syndrome. New York: Marcel Dekker, 1990:93-9.

9 Lippe BM. Turner's syndrome. In: Kaplan SA, ed. Clinical pediatric and adolescent endocrinology. Philadelphia: W B Saunders, 1982:272-92.

10 Ogata T, Tyler-Smith C, Purvis-Smith S, Turner G. Chromosomal location of a gene(s) for Turner stigmata on Yp. F Med Genet 1993;30:918-22.

11 Therman E, Susman B. The similarity of phenotypic effects caused by Xp and Xq deletions: a hypothesis. Hum Genet caused by Xp and

12 Ogata T, Petit C, Rappold G, Matsuo N, Matsumoto T, Goodfellow P. Chromosomal localization of a pseudoautosomal growth gene(s). I Med Genet 1992;29:624-8.

13 Sinclair AH, Berta P, Palmer MS, et al. A gene from the human sex-determinating region encodes a protein with homology to a conserved DNA-binding motif. Nature 1990;346:240-4

14 Gubbay J, Collignon J, Koopman P, et al. A gene mapping to the sex determining region of the mouse $\mathrm{Y}$ chromosome is a member of a novel family. Nature 1990;346:245-50. 